\title{
Genetic testing for Emberger syndrome
}

\author{
Yeltay Rakhmanov ${ }^{1}$, Paolo Enrico Maltese ${ }^{1 \star}$, Stefano Paolacci ${ }^{2}$, Alice Bruson ${ }^{1}$ and Matteo Bertelli ${ }^{1,2}$
}

\begin{abstract}
Emberger Syndrome (ES) is a very rare genetic disorder associated with primary lymphedema, myelodysplasia and immunodeficiency. The syndrome has autosomal dominant inheritance with incomplete penetrance. Sporadic cases caused by de novo germinal mutations in the GATA2 gene have also been described. We developed the test protocol on the basis of the latest research findings and diagnostic protocols on lymphatic malformation in ES. The genetic test is useful for confirming diagnosis, as well as for differential diagnosis, couple risk assessment and access to clinical trials.
\end{abstract}

Keywords: Primary lymphatic malformations, Emberger syndrome, GATA2 gene, EBTNA LAB UTILITY GENE TEST

'MAGI's Lab, Rovereto, Italy

${ }^{2}$ MAGI Euregio, Bolzano, Italy

*Corresponding author: P. E. Maltese E-mail: paolo.maltese@assomagi.org

DOI: $10.2478 /$ ebtj-2018-0028 (c) 2018 Authors. This work was licensed under the Creative Commons AttributionNonCommercial-NoDerivs 3.0 License.

\section{Emberger syndrome}

(Other synonyms: Primary lymphedema with myelodysplasia)

\section{General information about the disease}

Emberger syndrome (ES) is a very rare genetic disorder with primary lymphedema and myelodysplasia progressing to acute myeloid leukaemia (AML). ES may present as: primary lymphedema mostly of the lower extremities (unilateral or bilateral); genital lymphatic abnormalities (lymphedema, lymphangiectasis, hydrocele); myelodysplasia/ AML (low CD4/CD8); acute lymphangitis, multiple warts and deafness may develop due to immune dysfunction $(1,2)$. Other features that may be present are the following: hypotelorism, epicanthic folds, webbed neck, long and tapering fingers, and recurrent cellulitis (1).

The prevalence is not available, but is estimated to be very rare, less than 1 case per $1,000,000$ of population. The age of onset is, usually, during late childhood or puberty.

Clinical diagnosis should look for the above phenotypic manifestations through medical history, clinical assessments, lymphoscintigraphy, color Doppler echography, magnetic resonance, lymphangiography and testing for mutations in the coding region of the GATA2 gene.

ES (OMIM disease 614038) allelic disorders include immunodeficiency 21 (IMD21, OMIM disease 614172), acute myeloid leukemia (AML, OMIM disease 601626) and myelodysplastic syndrome (MDS, OMIM 614286) (3).

ES is caused by mutations in the GATA2 gene (OMIM gene 137295). GATA2 encodes a member of the GATA family of zinc-finger transcription factors. They are named after the consensus sequence they bind in the promoter regions of target genes (AGATAG). The encoded protein regulates EDN1 expression in endothelial cells and plays an essential role in regulating transcription of genes involved in stem cell maintenance, development and proliferation of hematopoietic and endocrine cell lineages, and adipogenesis (6). Furthermore, missense mutations found in GATA2 in ES patients result in a profoundly 
reduced capacity to bind enhancer elements upstream of lymphatic transcriptional regulators: PROX1, FOXC2 and NFATC1. In mice, conditional deletion of Gata2 revealed that the encoded protein is required for both development and maintenance of lymphovenous and lymphatic vessel valves (7).

The syndrome has autosomal dominant inheritance with incomplete penetrance, and sporadic cases due to de novo mutation have also been described (3).

Pathogenic variants may include missense, nonsense, splicing, small insertions and deletions.

\section{Aims of the test}

- To determine the gene defect responsible for the disease;

- To confirm clinical diagnosis;

- To assess the recurrence risk and perform genetic counselling for at-risk/affected individuals.

\section{Test characteristics}

\section{Specialist centers/ Published Guidelines}

The test is listed in the Orphanet database and is offered by 9 accredited medical genetic laboratories in the EU, and in the GTR database, offered by 5 accredited medical genetic laboratories in the US.

Guidelines for clinical use of the test are described in Genetics Home Reference (ghr.nlm.nih.gov).

\section{Test strategy}

Sanger sequencing is used for the detection of nucleotide variations in coding exons and flanking introns in the GATA2 gene. Sanger sequencing is also used for family segregation studies.

To perform molecular diagnosis, a single sample of biological material is normally sufficient. This may be $1 \mathrm{ml}$ peripheral blood in a sterile tube with $0.5 \mathrm{ml} \mathrm{K}$ EDTA or $1 \mathrm{ml}$ saliva in a sterile tube with $0.5 \mathrm{ml}$ ethanol $95 \%$. Sampling rarely has to be repeated. Gene-disease associations and the interpretation of genetic variants are rapidly developing fields. It is therefore possible that the genes mentioned in this note may change as new scientific data is acquired. It is also possible that genetic variants today defined as of "unknown or uncertain significance" may acquire clinical importance.

\section{Genetic test results \\ Positive}

Identification of pathogenic variants in the GATA2 gene confirms the clinical diagnosis and is an indication for family studies.

A pathogenic variant is known to be causative for a given genetic disorder based on previous reports, or predicted to be causative based on loss of protein function or expected significant damage to proteins or protein/protein interactions. In this way it is possible to obtain a molecular diagnosis in new/other subjects, establish the risk of recurrence in family members and plan preventive and/or therapeutic measures.

\section{Inconclusive}

Detection of a variant of unknown or uncertain significance (VUS): a new variation without any evident pathogenic significance or a known variation with insufficient evidence (or with conflicting evidence) to indicate it is likely benign or likely pathogenic for a given genetic disorder. In these cases, it is advisable to extend testing to the patient's relatives to assess variant segregation and clarify its contribution. In some cases, it could be necessary to perform further examinations/tests or to do a clinical reassessment of pathological signs.

\section{Negative}

The absence of variations in the genomic regions investigated does not exclude a clinical diagnosis but suggests the possibility of:

- alterations that cannot be identified by sequencing, such as large rearrangements that cause loss (deletion) or gain (duplication) of extended gene fragments;

- sequence variations in gene regions not investigated by this test, such as regulatory regions (5' and 3' UTR) and deep intronic regions;

- variations in other genes not investigated by the present test.

\section{Unexpected}

Unexpected results may emerge from the test, for example information regarding consanguinity, absence of family correlation or other genetically based diseases.

\section{Risk for progeny}

In autosomal dominant transmission, the probability that an affected carrier transmit the variant to his/her children is $50 \%$ in any pregnancy, irrespective of the sex of the child conceived.

\section{Limits of the test}

The test is limited by current scientific knowledge regarding the gene and disease.

\section{Analytical sensitivity (proportion of positive} tests when the genotype is truly present) and specificity (proportion of negative tests when the genotype is not present)

SANGER Analytical sensitivity $>99.99 \%$; Analytical specificity $99.99 \%$.

Clinical sensitivity (proportion of positive tests if the disease is present) and clinical specificity (proportion of negative tests if the disease is not present)

Clinical sensitivity: the complete sequencing of the GATA2 gene in 8 subjects with Emberger syndrome (2 family cases and 6 sporadic cases) allowed the identification of a variation in all probands $(8 / 8,100 \%)$ and all affected family members $(6 / 6 ; 100 \%)(2)$. Kazenwadel et al. reported another 2 cases 
with GATA2 variation and a phenotype overlapping with Emberger Syndrome (6). Recently a gene frameshift variation has been identified in a Korean patient (7).

Clinical specificity is estimated at approximately $99.99 \%$ (Author's laboratory data) (8).

\section{Prescription appropriateness}

The genetic test is appropriate when:

a) the patient meets the diagnostic criteria for ES;

b) the sensitivity of the test is greater than or equal to that of tests described in the literature.

\section{Clinical utility}

\section{Clinical management}

Confirmation of clinical diagnosis

Differential diagnosis

Couple risk assessment

\section{Utility}

Yes Yes Yes

Availability of clinical trials can be checked on-line at https://clinicaltrials.gov/

\section{References}

1. Mansour S, Connell F, Steward C, Ostergaard P, Brice G, Smithson S, Lunt $P$, Jeffery S, Dokal I, Vulliamy T, Gibson B, Hodgson S, Cottrell S, Kiely L, Tinworth L, Kalidas K, Mufti G, Cornish J, Keenan R, Mortimer P, Murday V; Lymphoedema Research Consortium. Emberger syndrome-primary lymphedema with myelodysplasia: report of seven new cases. Am J Med Genet A 2010;152A(9): 2287-96.
2. Ostergaard P, Simpson MA, Connell FC, Steward CG, Brice G, Woollard WJ, Dafou D, Kilo T, Smithson S, Lunt P, Murday VA, Hodgson S, Keenan R, Pilz DT, Martinez-Corral I, Makinen T, Mortimer PS, Jeffery S, Trembath RC, Mansour S. Mutations in GATA2 cause primary lymphedema associated with a predisposition to acute myeloid leukemia (Emberger syndrome). Nat Genet 2011; 43(10): 929-31.

3. S Michelini, M Cardone, M Haag O Agga, A Bruson, PE Maltese, A Bonizzato, $M$ Bertelli. A rare case of emberger syndrome caused by a de novo mutation in the Gata2 Gene. Lymphology. 2016; 49(1): 15-20.

4. http://www.genecards.org/cgi-bin/carddisp.pl?gene=GATA2\&keywords=gata2

5. Kazenwadel J, Betterman KL, Chong CE, Stokes PH, Lee YK, Secker GA, Agalarov Y, Demir CS, Lawrence DM, Sutton DL, Tabruyn SP, Miura N, Salminen M, Petrova TV, Matthews JM, Hahn CN, Scott HS, Harvey NL. GATA2 is required for lymphatic vessel valve development and maintenance. J Clin Invest. 2015; 125(8): 2979-2994.

6. Kazenwadel J, Secker GA, Liu YJ, Rosenfeld JA, Wildin RS, Cuellar-Rodriguez J, Hsu AP, Dyack S, Fernandez CV, Chong CE, Babic M, Bardy PG, Shimamura A, Zhang MY, Walsh T, Holland SM, Hickstein DD, Horwitz MS, Hahn CN, Scott HS, Harvey NL. Lossof-function germline GATA2 mutations in patients with MDS/AML or MonoMAC syndrome and primary lymphedema reveal a key role for GATA2 in the lymphatic vasculature. Blood 2012; 119(5): 1283-1291.

7. Sang Kyung Seo, Kyu Yeun Kim, Seo Ae Han, Joon Seok Yoon, Sang-Yong Shin, Sang Kyun Sohn, and Joon Ho Moon. First Korean case of Emberger syndrome (primary lymphedema with myelodysplasia) with a novel GATA2 gene mutation. Korean J Intern Med 2016; 31(1): 188-190.

8. Chen B, Gagnon M, Shahangian S, Anderson NL, Howerton DA, Boone JD; Centers for Disease Control and Prevention (CDC). Good Laboratory Practices for Molecular Genetic Testing for Heritable Diseases and Conditions. MMWR Recomm Rep. 2009; 58 (RR-6): 1-37. 